\title{
Embryological variation during nematode development ${ }^{*}$
}

\author{
Einhard Schierenberg ${ }^{\S}$, Zoological Institute, University of Cologne, \\ D-50923 Köln, Germany
}

\section{Table of Contents}

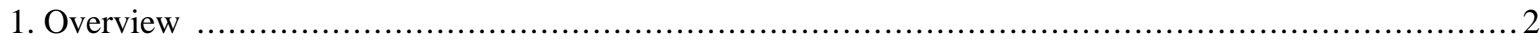

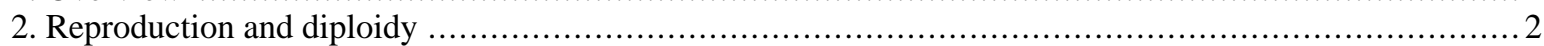

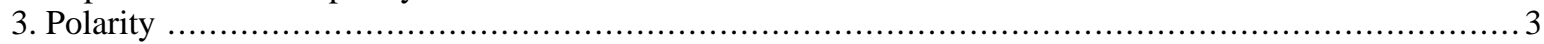

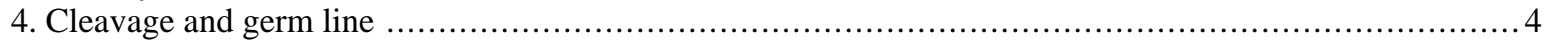

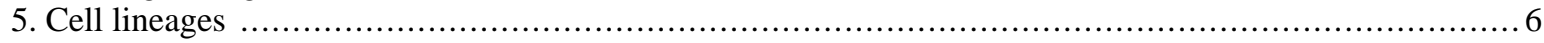

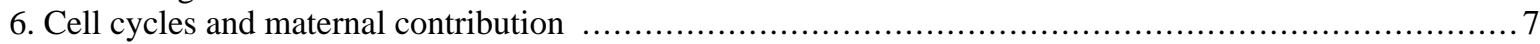

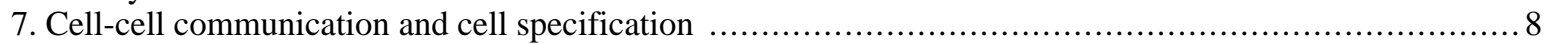

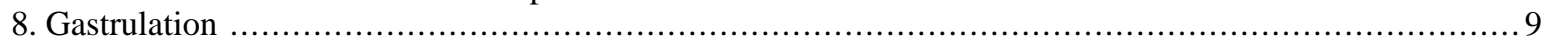

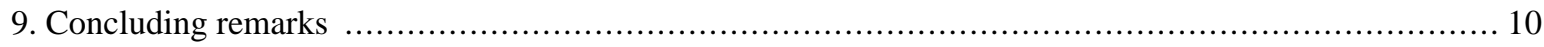

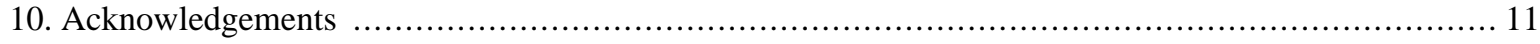

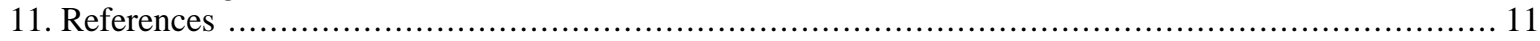

\begin{abstract}
Early cell lineages and arrangement of blastomeres in $C$. elegans are similar to the pattern found in Ascaris and other studied nematodes leading to the assumption that embryonic development shows little variation within the phylum Nematoda. However, analysis of a larger variety of species from various branches of the phylogenetic tree demonstrate that prominent variations in crucial steps of early embryogenesis exist among representatives of this taxon. So far, most of these variations have only been studied on a descriptive level and thus essentially nothing is known about their molecular or genetic basis. Nevertheless, it is obvious that the limited morphological diversity of the freshly hatched juvenile and the uniformity of the basic body plan contrast with the many modifications in the way a worm is generated from the egg cell. This chapter focuses on the initial phase between egg activation and gastrulation and deals with the following aspects: reproduction and diploidy, polarity, cleavage and germ line, cell lineages; cell cycles and maternal contribution, cell-cell communication and cell specification, gastrulation.
\end{abstract}

\footnotetext{
"Edited by James M. Priess and Geraldine Seydoux. Last revised April 28, 2005. Published January 02, 2006. This chapter should be cited as: Schierenberg, E. Embryological variation during nematode development (January 02, 2006), WormBook, ed. The C. elegans Research Community, WormBook, doi/10.1895/wormbook.1.55.1, http://www.wormbook.org.

Copyright: ( 92006 Einhard Schierenberg. This is an open-access article distributed under the terms of the Creative Commons Attribution License, which permits unrestricted use, distribution, and reproduction in any medium, provided the original author and source are credited

${ }^{\S}$ To whom correspondence should be addressed. E-mail: e.schierenberg@ uni-koeln.de
} 


\section{Overview}

Embryogenesis of $C$. elegans has been studied in detail (see Asymmetric cell division and axis formation in the embryo). As the early cell lineages and arrangement of blastomeres (Sulston et al., 1983) were found to be similar to the classic model Ascaris (Boveri, 1899) and other studied representatives of the phylum (Skiba and Schierenberg, 1992), the implicit assumption has been that the pattern of embryonic development is very similar among nematodes. However, as we know now, this conception is inaccurate. More recent analysis of a larger variety of species (see below) and older data from Russian researchers, which only became available with the English translation of Malakhov's (1994) book on nematodes, demonstrate that prominent variations in crucial steps of early embryogenesis exist (Goldstein, 2001). So far, most of these variations have only been studied on a descriptive level and thus essentially nothing is known about their molecular or genetic basis. Nevertheless, it is obvious that the limited morphological diversity of the freshly hatched juvenile (e.g., structure of mouth, pharynx, and tail) and the uniformity of the basic body plan contrast with the many modifications in the way a worm is generated from the egg cell. Often species-or even group-specific structural peculiarities like large body size, gonadal structure or appendages develop only during the postembryonic phase. As the vast majority of variations have been discovered during early embryogenesis, this chapter focuses on the initial phase between egg activation and gastrulation. The assumed phylogenetic position of all taxa mentioned in the text can be deduced from Figure 1. For easier reference the assignment of species to a specific clade according to Blaxter et al. (1998) is given in parantheses.

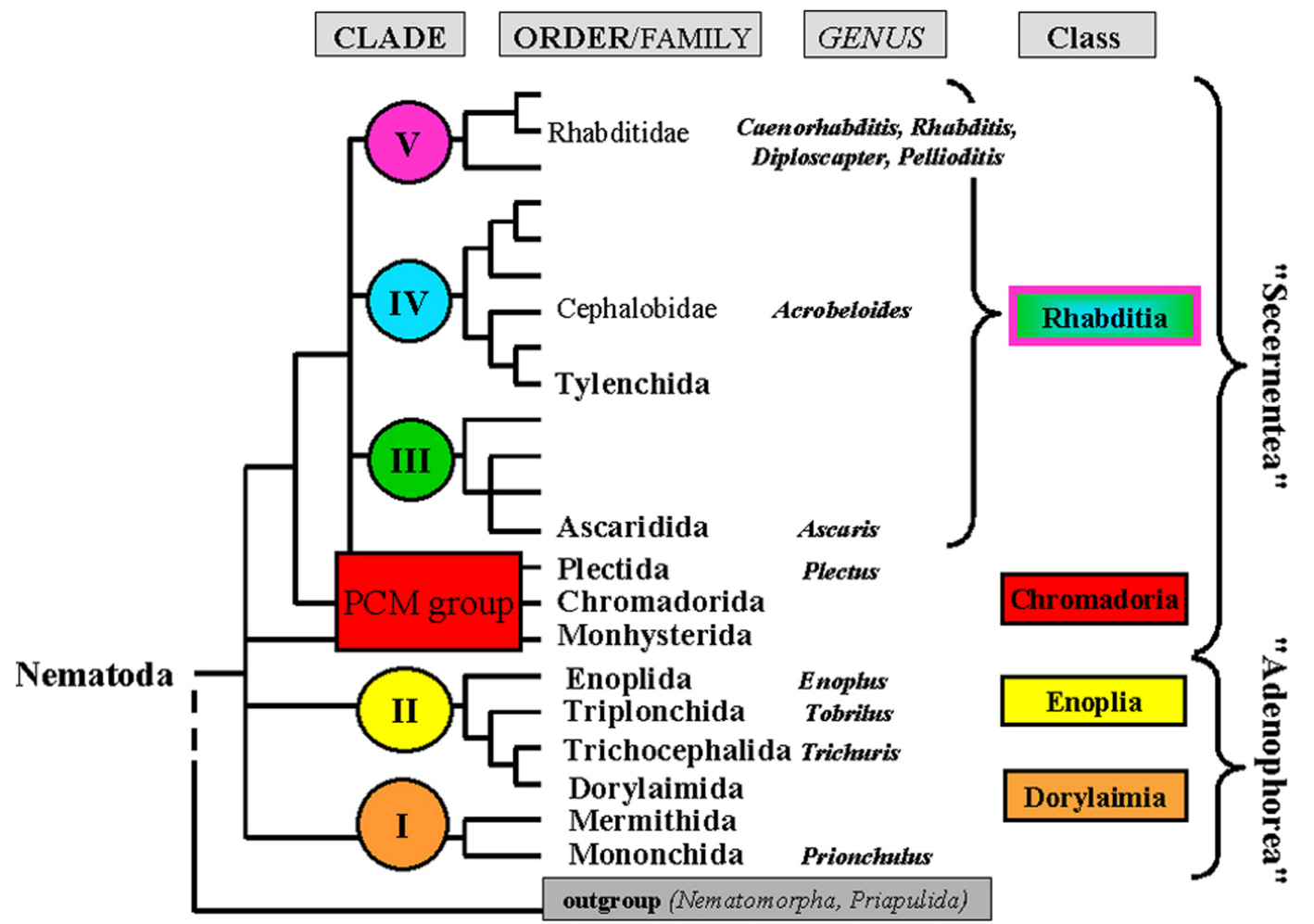

Figure 1. Phylogenetic tree of nematodes. Based on 18s RNA gene sequences, five different clades (I-V) have been defined. Branches that could not be

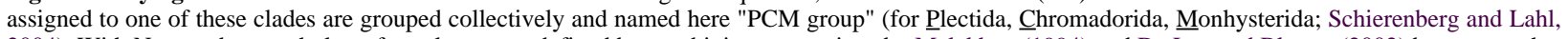
2004). With Nematoda as a phylum, four classes are defined by combining suggestions by Malakhov (1994) and De Ley and Blaxter (2002) because such a subdivision fits best our embryological data. Each genus mentioned in this chapter is indicated. Adapted from Blaxter et al. (1998).

\section{Reproduction and diploidy}

Nematodes show various modes of reproduction (Laugsch and Schierenberg, 2004) including parthenogenesis which is frequently found in some taxa like Cephalobidae or Plectida (Figure 1). In comparison to the situation in bisexual or hermaphroditic species, parthenogenesis requires a number of modifications during oogenesis or embryogenesis including the preservation or restoration of diploidy in the absence of sperm. The finding that haploid $C$. elegans embryos arrest during the second half of embryogenesis (Schierenberg and Wood, 1985) 
indicates that a diploid status is crucial for normal development. How diploidy is achieved in embryos of three parthenogenetic species, Diploscapter coronatus, Acrobeloides nanus and Plectus sp. (lab designation ES 601) can be deduced from the pattern of meiotic divisions accompanying the formation of polar bodies (PBs). In C. elegans (clade V) two PBs are generated as a result of two consecutive meiotic divisions (Figure 2a). In D. coronatus, a close relative of $C$. elegans (see Figure 1), also two PBs are present (Figure 2b), however, these result from a mitotic division of the first PB. In A. nanus (clade IV) usually only one large PB is formed (Figure 2c). Thus, in these two species the diploid status is evidently reached via a truncated meiosis. In contrast, in Plectus sp.(PCM group) two PBs are formed (Figure 2d) in a regular two-step meiosis. Preliminary data suggest that here an extra DNA replication cycle is inserted before first cleavage to restore diploidy.

Thus, variant solutions appear to exist for the same developmental challenge, i.e. establishment of diploidy. Together with the scattered phylogenetic distribution of parthenogenetic species these findings support the view that parthenogenetic reproduction has been acquired independently in different branches of the nematode phylum.
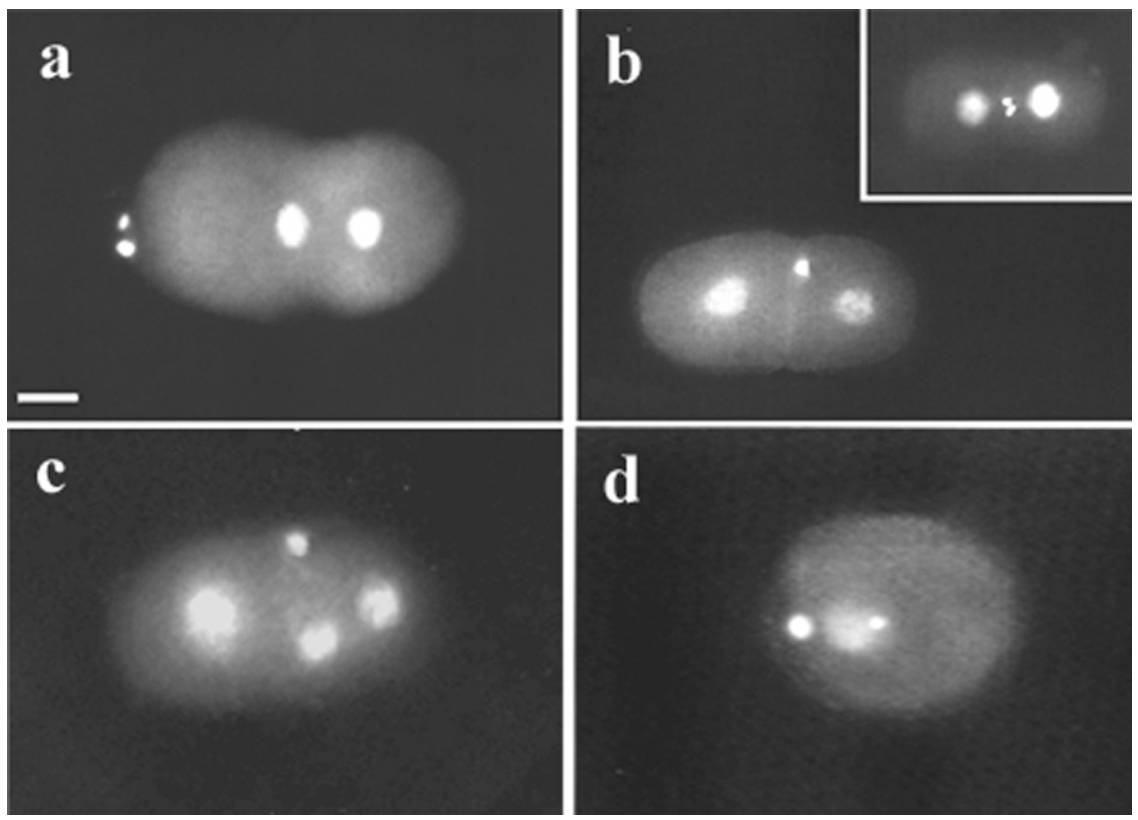

Figure 2. Variations in meiosis and polar body (PB) formation. Epifluorescence visualizing DAPI-stained nuclei. a, C. elegans, 1-cell embryo prior to fusion of pronuclei; two PBs have been extruded at the anterior pole as the result of two consecutive meiotic divisions; b, D. coronatus, 2-cell stage, one PB present; insert: 2-cell embryo after division of the single PB; c, A. nanus, 3-cell stage, one PB present; d, Plectus sp. (ES 601) 1-cell stage with two PBs produced in two meiotic divisions. Scale bar, $10 \mu \mathrm{m}$.

\section{Polarity}

It has been shown in C. elegans that the sperm has another important function for embryogenesis besides contributing its DNA and centrosome. Its entrance into the egg induces the primary polarity, i.e. defines the posterior pole (Goldstein and Hird, 1996) whereby the primary spatial cue derives from microtubules emanating from the sperm asters (Wallenfang and Seydoux, 2000, see Control of oocyte meiotic maturation and fertilization). As oocytes of C. elegans are usually fertilized at the pole that enters the spermatheca first, cleaving embryos in the uterus point (with few exceptions) with their posterior pole towards the vulva (Figure 3a).

Despite the absence of sperm, parthenogenetic nematodes express an anterior-posterior (a-p) polarity similar to $C$. elegans in that with their first cleavage they generate a larger somatic cell $\mathrm{AB}$ and a smaller germ line cell $\mathrm{P}_{1}$.

In A. nanus (clade IV) embryos point (with few exceptions) with their anterior pole toward the vulva (Figure $3 b)$. Thus, here some external cue other than sperm seems to induce the direction of egg polarity. A similar conclusion has been drawn by Goldstein et al. (1998) for a bisexual Acrobeloides species where the position of the sperm bears no consistent relationship to embryonic polarity. Their data suggest that in the suborder Cephalobinae, independent of the mode of reproduction, a different mechanism has evolved to establish embryonic polarity. As in C. elegans the meiotic spindle can induce polarity under certain circumstances (Wallenfang and Seydoux, 2000) it 
may play a role in the establishment of the "reversed" polarity in A. nanus embryos. In D. coronatus (clade V), half of the embryos point with their anterior pole toward the vulva and half with their posterior pole (Figure $3 \mathrm{c}, \mathrm{d}$ ). Hence, fixation of the a-p orientation in the egg cell seems to occur in a random fashion independent of an external signal. Thus, there are obviously different ways among nematodes for embryonic polarity to be established prior to first cleavage.
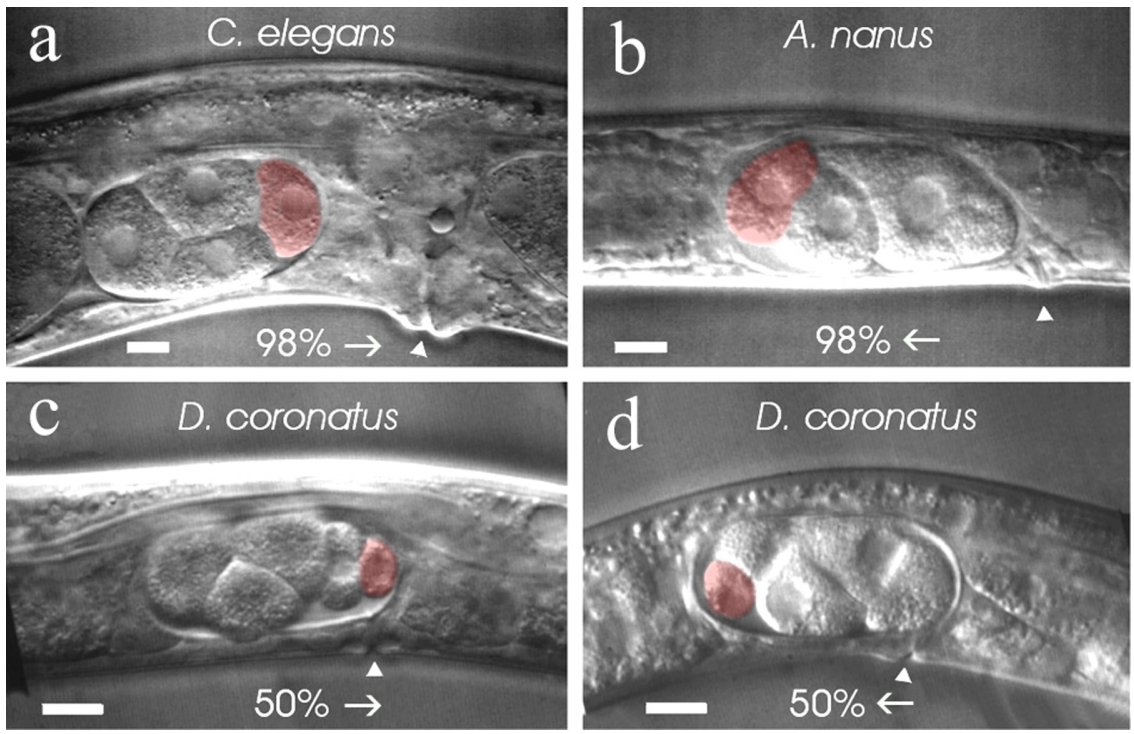

Figure 3. Variations in the establishment of embryonic polarity. a, C. elegans, $98 \%$ of all embryos point with their posterior pole toward the vulva; b, A. nanus, $98 \%$ of all embryos point with their anterior pole toward the vulva; c, d, D. coronatus, equal proportions of embryos point with their anterior or posterior pole toward the vulva; arrows indicate orientation of eggs in the uterus; arrowheads, position of the vulva; red, posteriorly located germline cells $\mathrm{P}_{2}(\mathrm{a}, \mathrm{b})$ or $\mathrm{P}_{3}(\mathrm{c}, \mathrm{d})$. Scale bars, $10 \mu \mathrm{m}$. From Lahl et al., 2005.

\section{Cleavage and germ line}

In members of clades III-V plus the "PCM" group (Figure 1), the first cleavage goes along with a separation into a larger soma $(\mathrm{AB})$ and a smaller germ line cell $\left(\mathrm{P}_{1}\right)$. This process of soma/germ line separation continues during the following divisions finally resulting in the establishment of a small number of somatic founder cells and the primordial germ cell (see Specification of the germ line). This type of cleavage has been named "strong expression of the germ line" (Schierenberg and Lahl, 2004).

Representatives of clade I were found to behave differently (Malakhov, 1994; Lahl and Schierenberg, unpublished). In Trichuris muris the first division is extremely asymmetric but the following ones are more or less equal (Figure 4a,b) while in Prionchulus clear asymmetric cleavages can only be detected at a later stage (Figure 4c, d). This cleavage behavior, which may be characteristic for clade I, has been named "weak expression of the germ line" (Schierenberg and Lahl, 2004).

Even more dramatic deviations from the standard pattern are found in clade II. In the handful of species studied so far (Malakhov, 1994; Voronov, 1999; Schierenberg, 2004) no early asymmetric cleavages and thus no a-p polarity has been detected at all (Figure 5a, b). It remains to be determined whether in these species, which are all dioecious, a hidden early germ line exists or whether germ cells are generated via a different mechanism. At least the sperm does not have the same polarizing function in these species as it does in C. elegans. 

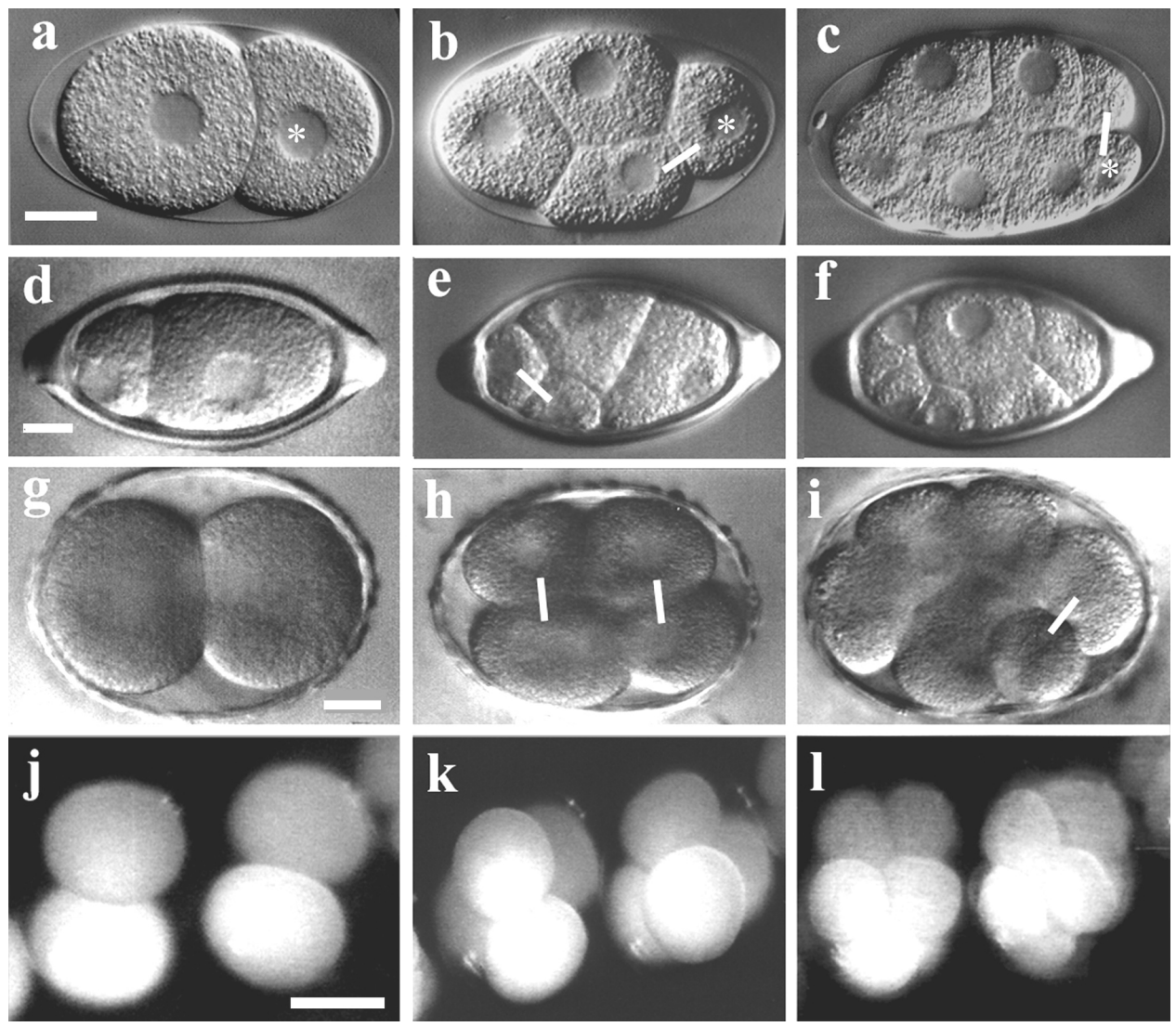

Figure 4. Variations in early cleavage pattern. a-c, C. elegans. a, With the first division a larger somatic cell $\mathrm{AB}$ (left) and a smaller germline cell $\mathrm{P}$ (right) are generated; b, 4-cell stage, $\mathrm{AB}$ has divided symmetrically with transverse spindle orientation, $\mathrm{P}$ has divided asymmetrically with longitudinal spindle orientation; c, 8-cell stage, germline cell $\mathrm{P}$ has divided asymmetrically; *, germline cells. d-f, Trichuris muris. d, 2-cell stage, an extremely asymmetric first cleavage has generated a smaller anterior and a larger posterior cell; e, 4-cell stage, both daughters have performed a symmetric division; f, 8-cell stage, no prominent asymmetric division has occurred. g-i, Prionchulus sp.; g, 2-cell stage resulting from a symmetric first cleavage; h, 4-cell stage, both daughter cells have divided symmetrically with transverse spindle orientation; i, 8-cell stage, one cell has performed a germline-like asymmetric division. j-1, Enoplus brevis, absence of early, asymmetric divisions giving no indication for the presence of a germ line; epi-illumination used because embryos are not transparent. Connecting lines, selected sister cells. Orientation: a-i, anterior, left. Scale bars: a-i, $10 \mu \mathrm{m}, \mathrm{j}-1,100 \mu \mathrm{m}$.

The germ line in C. elegans contains cytoplasmic granules which play an important role for the preservation of germ line identity (Strome et al., 1994; Seydoux and Schedl, 2001; see Specification of the germ line). Antibodies directed against these so-called $\mathrm{P}$ granules were found to also detect cellular structures in early embryos of other nematode species of clade IV and V. However, their localization can differ from the C. elegans pattern (Figure 5; Skiba and Schierenberg, 1992; Goldstein et al., 1998). In those cases where intranuclear components are detected in all cells (Figure 5c), the $C$. elegans antibodies seem to cross-react with structures unrelated to germ line.

A classical example for developmental variations among the nematodes is constituted by the case of "chromatin diminution" in Ascaris (clade III), where nearly all blastomeres lose a large fraction of their chromatin. Those few cells that do not were identified as germ line cells (Boveri, 1887) giving support for the earlier postulated "continuity of the germplasm" (Weismann, 1885). This unusual mode of making cells different from each other is not found in any of the other nematodes mentioned in this chapter but has apparently developed independently in a small number of unrelated species from different animal phyla. Its underlying mechanism and significance are only partly understood (Müller and Tobler, 2000; see A quick tour of nematode diversity and the backbone of nematode phylogeny). 


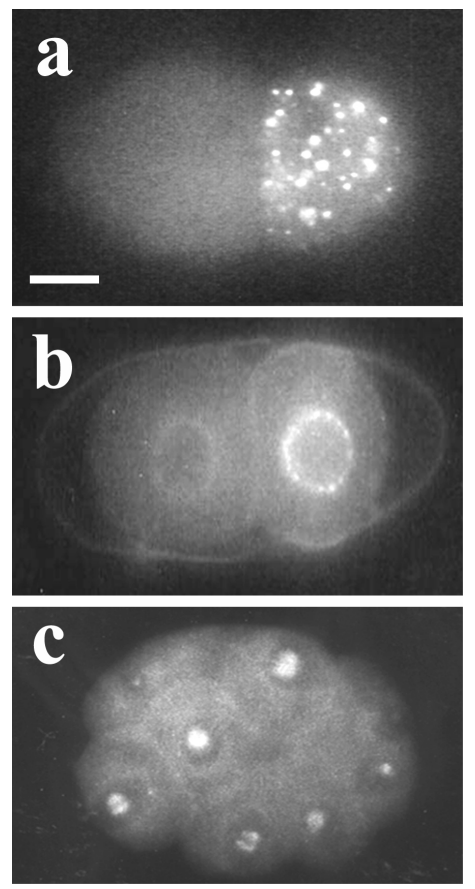

Figure 5. Variant staining with antibodies against $C$. elegans $\mathbf{P}$ granules. a, $C$. elegans, 2 -cell stage, $\mathrm{P}$ granules are only present in the germline cell $\mathrm{P}_{1}$; $\mathrm{b}$, A. nanus, 2-cell stage, strong perinuclear staining in the germline cell $\mathrm{P}_{1}$, weak staining in the somatic $\mathrm{AB}$ cell; $\mathrm{c}$, Rhabditis terricola. 8-cell stage, intranuclear staining in all blastomeres. Orientation: anterior, left. Scale bar, $10 \mu \mathrm{m}$.

\section{Cell lineages}

The impressively detailed studies on cellular development in the Ascaris (clade III) embryo more than a hundred years ago (Muller, 1903) strongly suggested the existence of invariant cell lineages. The complete description of C. elegans embryogenesis on a cell-by-cell basis (Sulston et al., 1983) revealed that it is very similar to Ascaris and gave proof that the old assumption was correct.

More recent analysis of nematodes embryogenesis in different clades uncovered that the order of early cleavages can vary considerably among species, particularly with respect to the germ line and can be correlated to the developmental tempo (Skiba and Schierenberg, 1992). While, for instance in C. elegans the primordial germ cell $\mathrm{P}_{4}$ is formed when $16 \mathrm{AB}$ cells have been already generated, in some Acrobeloides species, which develop several times slower, all embryonic germ line divisions are executed before any of the somatic cells divide (Schierenberg, 1997). Based on experiments where after artificially delayed divisions a reduced number of asymmetric germ line divisions took place, it was postulated that the preservation of germ line identity requires the timely separation from the soma (Schlicht and Schierenberg, 1991).

To fully appreciate how variable embryogenesis can be among nematodes, lineages have to be followed completely and terminal differentiation must be monitored. Besides C. elegans (Sulston et al. (1983), this has only been done in a close relative, Pellioditis marina (Houthoofd et al, 2003). It was found that lineage homology between the two species is very high (about 95\%) but fate homology considerably lower (about 75\%). The authors suggested that the differences in the fate distribution pattern are due to different compromises between minimizing the number of specification events and minimizing the need for time-consuming cell migrations.

In members of clade II, due to the absence of a visible germ line (see section 4) initially no cell lineages can be defined. All blastomeres look alike and occupy variable positions relative to each other. In Enoplus brevis at the 8-cell stage, one blastomere divides with some delay. This is the founder cell for the intestine generating the only cell lineage that has been identified so far. Other blastomeres appear to adopt variable fates at a later stage (see section 7).

In contrast to C. elegans and most of the other studied nematodes, in members of clades I and II the gut founder cell has been described to come from the anterior blastomere of the 2-cell stage (Malakhov, 1994; for a variable origin or an origin not related to the a-p axis in Enoplida, see Voronov and Panchin; 1998; Voronov, 1999). 


\section{Cell cycles and maternal contribution}

The duration of early embryonic cell cycles differs dramatically among nematodes. While in C. elegans they are as short as 10 minutes, in the marine E. brevis (clade II) they require 6 to 7 hours. The analysis of maternal-effect mutants demonstrates that in C. elegans early embryogenesis depends heavily on gene products already synthesized during oogenesis (Bowerman, 1998). Drug-induced inhibition of transcription revealed that the rapid cleavages including proper soma/germ line separation continue beyond the 100-cell stage under these conditions (Edgar et al., 1994). However, this does not apply for nematodes in general. In A. nanus (Wiegner and Schierenberg, 1998) but also in other Rhabditis species, without transcription cleavage ceases after a few divisions. In addition, cell cycle durations change over time. While for instance in $C$. elegans the tempo of $\mathrm{AB}$ cell cycles becomes slower, in A. nanus they become faster, and in Rhabditis dolichura they first become slower and then faster (Laugsch and Schierenberg, 2004). These variations can be explained with different availability of maternal and zygotic gene products (Figure 6).

a

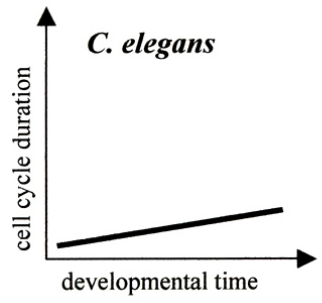

b

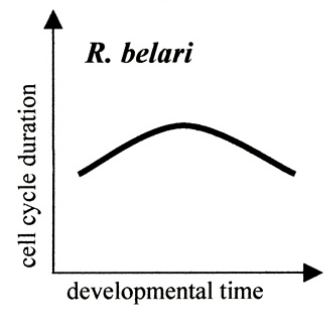

c

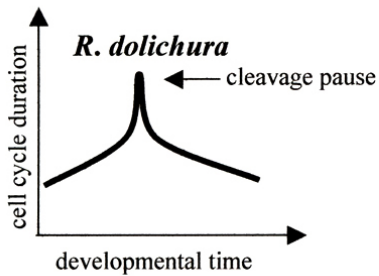

d

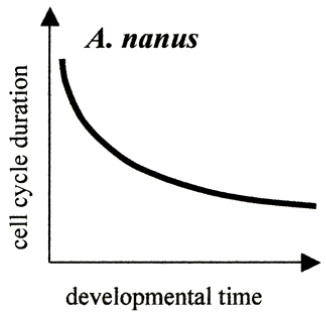

available gene products:

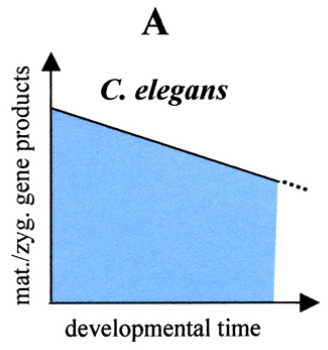

B

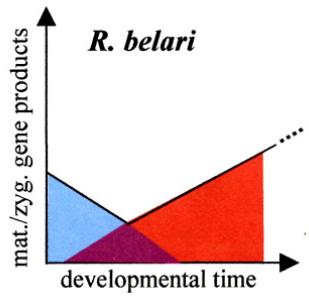

C

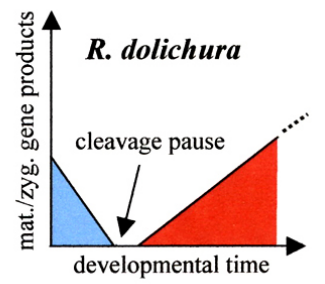

D

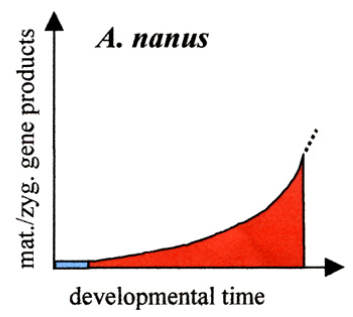

zygotic $\square \begin{gathered}\text { maternal } \\ \text { +zygotic }\end{gathered}$

Figure 6. Variations in cell cycle patterns. a-d, observations. Changes in cell cycle lengths of AB cells in four nematode species. A-D, interpretation. Proposed decrease of maternal and increase of zygotic components. Adapted from Laugsch and Schierenberg (2004). 


\section{Cell-cell communication and cell specification}

Cell-specification in C. elegans involves two mechanisms. First, early blastomeres are assigned different fates by unequally segregated maternal factors. Second, cell-cell interactions can modulate or completely alter the original developmental program of a cell (see Asymmetric cell division and axis formation in the embryo). Only few data are available on experimental analysis of cell specification in other nematode embryos. In E. brevis, where no germ line and only one somatic lineage have been detected (see sections 4 and 5), development of partial embryos and cell marking experiments (Voronov and Panchin, 1997) indicate that as a rule blastomeres are not specified early and embryos possess a considerable regulative potential.

Also a nematode much more closely related to $C$. elegans shows an unexpected degree of developmental plasticity. In A. nanus (clade IV) early blastomeres appear to compete for a primary fate (Wiegner and Schierenberg, 1999). After ablation of early blastomeres, the embryos can still develop into a juvenile because the remaining blastomeres switch their fates in a hierarchical manner (Figure 7). In the same species the spatial arrangement of posterior blastomeres varies considerably among individuals, prompting experiments wherein the role of the germ line as the source of inductions was investigated. They revealed that an induction of EMS by the germ line cell $\mathrm{P}_{2}$, as found in $C$. elegans (see Asymmetric cell division and axis formation in the embryo), is not required for proper specification of the gut precursor cell EMS. Here early somatic blastomeres are pluripotent and inhibiting interactions among them appear to ensure different cell fate assignments (Figure 8; Wiegner and Schierenberg, 1998).
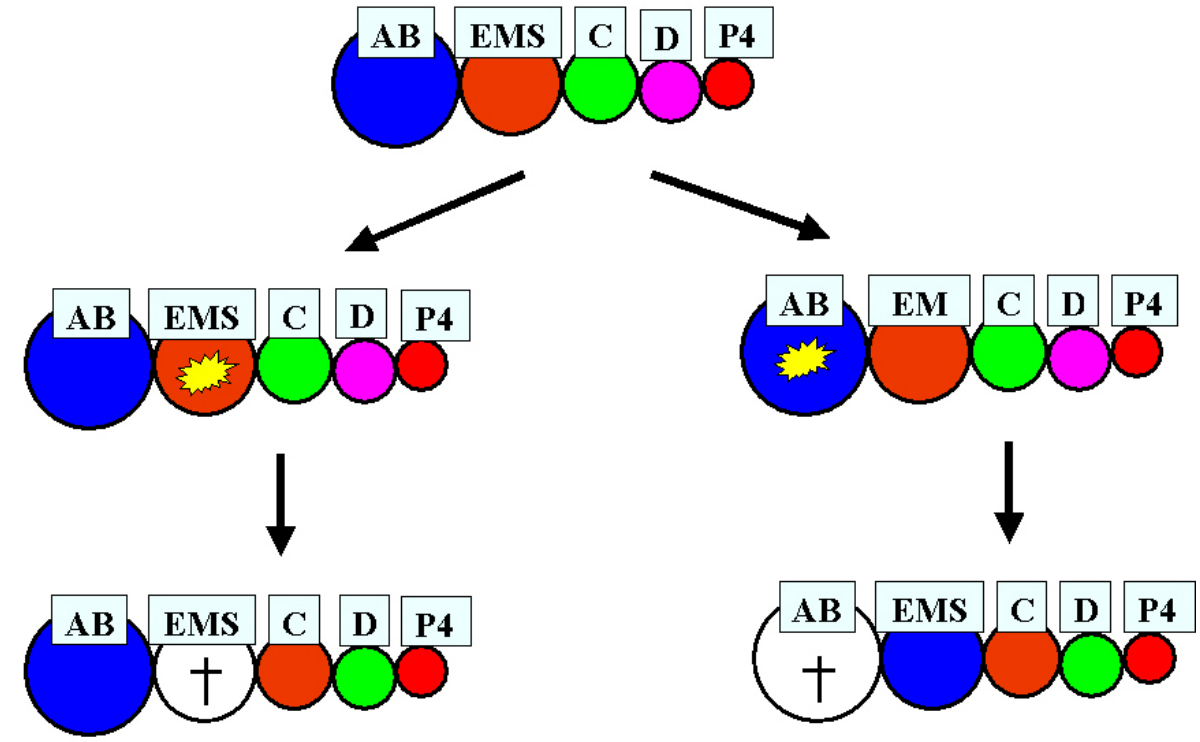

Figure 7. Cell fate transformations in manipulated $\boldsymbol{A}$. nanus embryos. Starting from an intact early embryo (top) with the sequentially generated somatic cells AB, EMS, C, D, and the primordial germ cell P, either EMS (left) or AB (right) is ablated. Consequently, specific cell fate transformations take place in somatic cells as indicated by changes in the color code but not in the germline. In both experiments the "D" cell fate (small fraction of body muscles) is probably lost. Nevertheless, development is compatible with the generation of fertile animals. Adapted from Schierenberg (2001).

A somewhat comparable situation seems to exist in D. coronatus (clade V). Here all early blastomeres are aligned along the a-p axis because a rotation of the nuclear-centrosome complex takes place, not only in cells of the germ line like in C. elegans (Hyman and White, 1987) but also in the anterior somatic blastomere AB. An induction of the germ line $\mathrm{P}$ making $\mathrm{ABp}$ different from $\mathrm{ABa}$ as found in C. elegans (Bowerman et al., 1992) does apparently not take place in this species, as cell arrangements are variable and $\mathrm{P}_{2}$ never touches ABp (Lahl and Schierenberg, unpublished). 


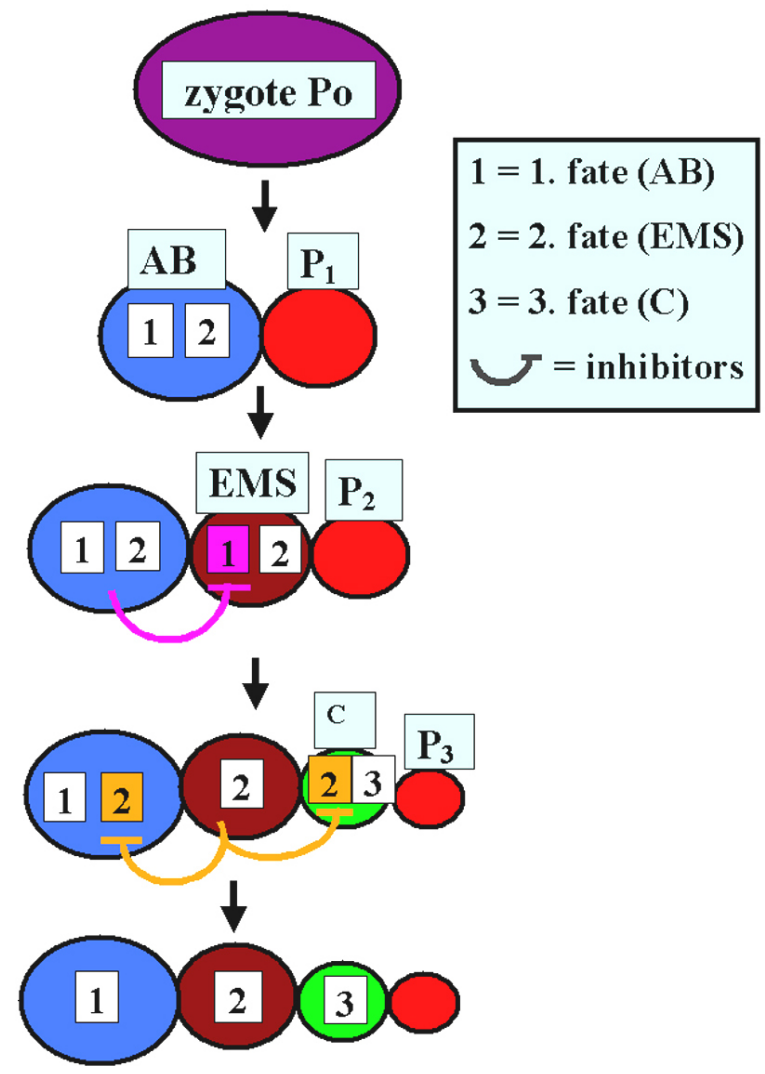

Figure 8. Model for cell specification in A. nanus. Early blastomeres can execute two alternative developmental programs $(1+2$ or $2+3)$. Competing for a primary fate, inhibiting interactions between neighboring cells lead to the restriction of developmental potential in a hierarchical manner. At least between $\mathrm{AB}$ and EMS reciprocal interactions take place.

\section{Gastrulation}

Gastrulation as seen in C. elegans leads to a triblastic embryo with only a rudimentary blastocoel present. It can be subdivided into two distinct phases, (i) ingression of the two gut precursors (E cells) starting at the 26-cell stage (Figure 9a) and (ii) immigration of a larger number of mesodermal progenitors derived from different lineages at a much higher cell stage (Sulston et al., 1983). Here only variations of the first step, the generation of a gut primordium, will be considered. This process appears to be similar in members of clades I, III, IV and V (Figure 1), even in Enoplida (Figure 9c, d) with their unusual cleavage pattern (Figure 4j-1). However, in Plectida ("PCM group") gastrulation starts as early as the 8-cell stage and it is always the gut founder cell itself that immigrates (Figure 9b; Lahl et al., 2003). Other members of the "PCM group" (Chromadorida, Monhysterida) show the same phenomenon (Malakhov, 1994; Schierenberg and Lahl, 2004; E.S., unpublished).

The most unexpected variant, however, is seen in Tobrilus diversipapillatus, a member of the Triplonchida (clade II). Here, in contrast to all other nematodes studied so far, a large blastocoel is formed and cells migrate into this cavity after the 64-cell stage (Schierenberg, 2005; Figure 9e, f). Thus, this species follows the "classical" type widely distributed in the animal kingdom which is considered a plesiomorphic character (Arendt, 2004). Structural and molecular analyses suggest that clade II may represent the most ancient branch of nematodes (Malakhov, 1994; Aleshin et al., 1998). The developmental findings demonstrate that within the nematode phylum not only a switch from one cleavage type to another (see section 4) has taken place but also from one type of gastrulation to another. So far no obvious correlations have been found between the type of gastrulation and other developmental parameters like embryo size, cell numbers or developmental tempo (Schierenberg, 2005). 

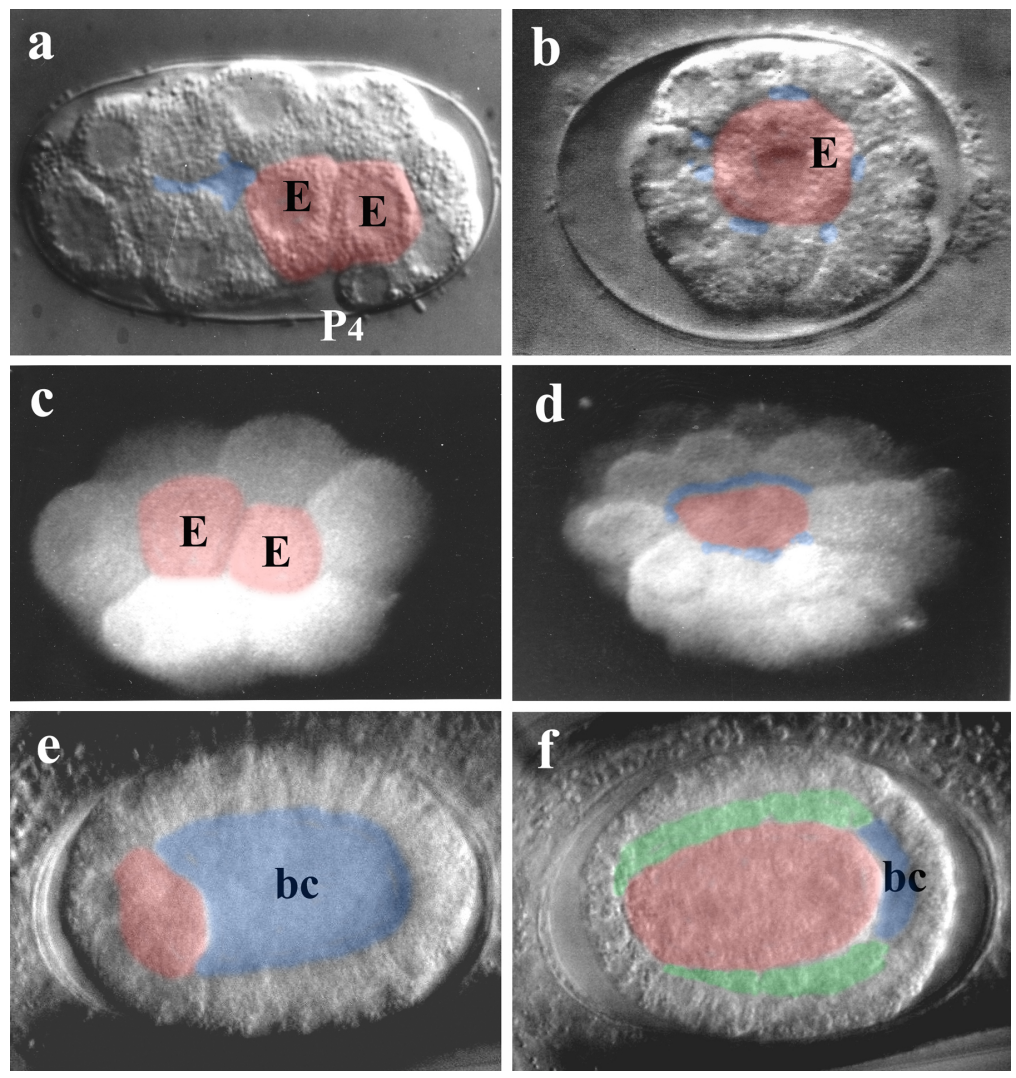

Figure 9. Variations in gastrulation. a, C. elegans. Both descendants of the E cell (gut founder) have moved into the interior of the embryo after the 24-cell stage, only rudimentary blastocoel present. b, Plectus sp. (ES 601). The E cell has moved inside the embryo after the 12-cell stage. c, Enoplus brevis, 16-cell stage, two gut precursor cells have started to immigrate. D, same embryo as in c, ca. 64-cell stage, through the blastopore part of the immigrated gut precursors are visible. e, Tobrilus diversipapillatus. After the 64-cell stage gut precursors have started to move into the large blastocoel (bc) from the anterior region. $\mathrm{f}$, same embryo as in e, most of the blastocoel is filled with immigrated cells. Between outer and inner cells a third layer has formed. Color code, blue, blastocoel; red, gut precursor cells (endoderm; in d, probably including pharyngeal precursors); green, intermediate layer ("mesoderm"). Orientation: anterior, left. Bars, $10 \mu \mathrm{m}$.

\section{Concluding remarks}

The data summarized in this chapter document that embryogenesis in nematodes is more variable than the final product, the hatching juvenile, would predict. While unexpectedly large genetic differences exist even between closely related nematode species (Fitch et al., 1997), their special body plan apparently prevented a corresponding degree of morphological diversification as found in other phyla like arthropods or vertebrates. The wealth of early developmental variations appears paradoxical in a way, as these do not have any obvious impact on structure or performance of the resulting worms. Why then are there different ways to reach essentially the same goal? Two explanations appear possible. It could either be a result of neutral evolution, i.e. variations are due to system-inherent plasticity without any adaptive value. Alternatively, the different ways may reflect alternative developmental strategies to increase fitness, for instance by making production faster or cheaper (Schierenberg, 2001).

It is not immediately clear why early embryogenesis should be more variable than later phases. One argument has been that development is modular and integration of the emerging modules increases over time, putting fewer constraints on early development (Raff, 1996). This seems reasonable for organisms where cells are specified relatively late, like vertebrates and may-be very slow developing nematodes like Enoplids. However, in the $C$. elegans type of development, essential decisions requiring intercellular communication have been shifted to a very early phase. Thus, it can be questioned whether this argument is valid for fast developing nematodes.

In order to correlate ontogeny and phylogeny, embryonic variations may be useful heuristically as phylogenetic markers in addition to morphology and molecules because (i) they are potentially independent of these parameters and (ii) they constitute events rather than structures and therefore represent a different quality of information (Schierenberg, 2001). By looking at processes like axis specification (Goldstein et al.; 1998), cleavage 
pattern, arrangement of blastomeres (Dolinski et al., 2001), germ line behavior and gastrulation (Schierenberg and Lahl, 2004; Schierenberg, 2005), attempts have been made to trace the evolution of embryonic diversity in nematodes.

By extending comparative studies to a larger number of species and by identifying relevant genes, we should learn more about the intrinsic prerequisites for the implementation of embryonic novelty. It will be even more ambitious to try to understand to what extent the Darwinian rules of variation and selection apply to developmental processes and how the interplay between internal genetic provision and external conditions determines the chance for a deviation from an original embryonic pattern to arise and to succeed.

\section{Acknowledgements}

Much of the work performed in my laboratory was supported by the Deutsche Forschungsgemeinschaft, partly through SFB 572.

\section{References}

Aleshin, V.V., Kedrova, O.S., Milyutina, I.A., Vladychenskaya, N.S., Petrov, N.B. (1998). Relationships among nematodes based on the analysis of 18S rRNA gene sequences: molecular evidence for monophyly of Chromadorian and Secernentean nematodes. Russ. J. Nematol. 6, 175-184.

Arendt, D. (2004). Comparative aspects of gastrulation. In: Gastrulation-from cells to embryo, C.D. Stern, ed. (New York, NY: Cold Spring Harbor Laboratory Press), pp. 679-693.

Blaxter, M.L., De Ley, P., Garey, J.R., Liu, L.X., Scheldeman, P., Vierstraete, A., Vanfleteren, J.R., Mackey, L.Y., Dorris, M., Frisse, L.M., Vida, J.T., Thomas, W.K. (1998). A molecular evolutionary framework for the phylum Nematoda. Nature 392, 71-75. Article

Boveri, T. (1887). Über die Differenzierung der Zellkerne während der Furchung des Eies von Ascaris megalocephala. Anat. Anzeiger 2, 668-693.

Boveri, T. (1899). Die Entwickelung von Ascaris megalocephala mit besonderer Rücksicht auf die Kernverhältnisse. In Festschrift für C. v. Kupffer. (Jena: Gustav Fischer Verlag), pp. 383-430.

Bowerman, B. (1998). Maternal control of pattern formation in early Caenorhabditis elegans embryos. Curr. Top. Dev. Biol. 39, 73-117. Abstract

Bowerman, B., Tax, F.E., Thomas, J.H., and Priess, J.R. (1992). Cell interactions involved in development of the bilaterally symmetrical intestinal valve cells during embryogenesis in Caenorhabditis elegans. Development 116, 1113-1122. Abstract

De Ley, P., and Blaxter, M. (2002). Systematic position and phylogeny. In: The biology of nematodes. D.L. Lee, ed. (London: Taylor and Francis), pp 1-30.

Dolinski, C., Baldwin J.G., and Thomas, W.K. (2001). Comparative survey of early embryogenesis of Secernentea (Nematoda), with phylogenetic implications. Can. J. Zool. 79, 82-94. Article

Edgar, L.G., Wolf, N., and Wood, W.B. (1994). Early transcription in Caenorhabditis elegans embryos. Development 120, 443-451. Abstract

Fitch, D.H.A., and Thomas, W.K. (1997). Evolution. In: C. elegans II, D.L. Riddle, T. Blumenthal, B.J. Meyer, and J.R. Priess, eds. (New York, NY. Cold Spring Harbor Laboratory Press), pp 815-850.

Goldstein, B. (2001). On the evolution of early development in the Nematoda. Philos. Trans. R. Soc. Lond. 356, 1521-1531. Abstract Article

Goldstein, B., and Hird, S.N. (1996) Specification of the anteroposterior axis in Caenorhabditis elegans. Development 122, 1467-1474. Abstract 
Goldstein, B., Frisse, L.M., and Thomas, W.K. (1998). Embryonic axis specification in nematodes: evolution of the first step in development. Curr. Biol. 8, 157-60. Abstract Article

Houthoofd, W., Jacobsen, K., Mertens, C., Vangestel, S., Coomans, A., Borgonie, G. (2003). Embryonic cell lineage of the marine nematode Pellioditis marina. Dev. Biol. 258, 57-69. Abstract Article

Hyman, A.A., and White, J.G. (1987). Determination of cell division axes in the early embryogenesis of Caenorhabditis elegans. J. Cell Biol. 105, 2123-2135. Abstract Article

Lahl, V., Sadler, B., Schierenberg, E. (2005). Egg development in parthenogenetic nematodes: variations in meiosis and axis formation. Int. J. Dev. Biol. (in press).

Lahl, V., Halama, C., Schierenberg, E. (2003). Comparative and experimental embryogenesis of Plectidae (Nematoda). Dev. Genes Evol. 213, 18-27. Abstract Article

Laugsch, M., and Schierenberg, E. (2004). Differences in maternal supply and early development of closely related nematode species. Int. J. Dev. Biol. 48, 655-662. Abstract Article

Malakhov, V.V. (1994). Nematodes, Structure, Development, Classification and Phylogeny. (Washington, DC: Smithsonian Institution Press).

Müller, H. (1903). Beitrag zur Embryonalentwickelung der Ascaris megalocephala. Zoologica 41, 1-30.

Müller, F., Tobler, H. (2000). Chromatin diminution in the parasitic nematodes Ascaris suum and Parascaris univalens. Int. J. Parasitol. 30, 391-399. Abstract Article

Raff, R.A. (1996). The Shape of Life. (Chicago, IL: University of Chicago Press).

Schierenberg, E. (1997). Nematodes: the roundworms. In: Embryology. Constructing the Organism, S.F. Gilbert, and A.M. Raunio, eds. (Sunderland, MA: Sinauer Associates), pp. 131-147.

Schierenberg, E. (2001). Three sons of fortune: early embryogenesis, evolution and ecology of nematodes. BioEssays 23, 841-847. Abstract Article

Schierenberg, E. (2005). Unusual cleavage and gastrulation in a freshwater nematode: developmental and phylogenetic implications. Dev. Genes Evol. 215, 103-108. Abstract Article

Schierenberg, E., and Wood, W.B. (1985). Control of cell-cycle timing in early embryos of C. elegans. Dev. Biol. 107, 337-354. Abstract Article

Schierenberg, E., and Lahl, V. (2004). Embryology and phylogeny of nematodes. In Nematology Monographs\& Perspectives, Vol. 2, Cook, R.C., and Hunt, D.J. eds. (Leiden: Brill), pp. 667-679.

Schlicht, P, and Schierenberg, E, (1991). Altered establishment of cell lineages in theCaenorhabditis elegans embryo after suppression of the first cleavage supports a concentration-dependent decision mechanism. Roux's Arch. Dev. Biol. 199, 437-448. Article

Seydoux, G., and Schedl, T. (2001). The germline in C. elegans: origins, proliferation, and silencing. Int. Rev. Cytol. 203, 139-185. Abstract

Skiba, F., and Schierenberg, E. (1992). Cell lineages, developmental timing, and spatial pattern formation in embryos of free-living soil nematodes. Dev. Biol. 151, 597-610. Abstract Article

Strome, S., Garvin, C., Paulsen ,J., Capowski, E., Martin, P., and Beanan M. (1994). Specification and development of the germline in Caenorhabditis elegans.Ciba Found. Symp. 182, 31-45. Abstract

Sulston, J.E., Schierenberg, E., White, J.G., and Thomson, J.N. (1983). The embryonic cell lineage of the nematode C. elegans. Dev. Biol. 100, 64-119. Abstract Article 
Voronov, D.A. (1999). The embryonic development of Pontonema vulgare (Enoplida: Oncholaimidae) with discussion of nematode phylogeny. Russ. J. Nematol. 7, 105-114.

Voronov, D.A., and Panchin, Y.V. (1998). Cell lineage in marine nematode Enoplus brevis. Development 125, 143-150. Abstract Article

Wallenfang, M.R., and Seydoux, G. (2000). Polarization of the anterior-posterior axis of C. elegans is a microtubule-directed process. Nature 408, 89-92. Abstract Article

Weismann, A. (1885). Die Continuität des Keimplasmas als Grundlage einer Theorie der Vererbung. (Jena: Gustav Fischer Verlag).

Wiegner, O., and Schierenberg, E. (1998). Specification of gut cell fate differs significantly between the nematodes A. nanus and C. elegans. Dev. Biol. 204, 3-14. Abstract Article

Wiegner, O., Schierenberg, E. (1999). Regulative development in a nematode embryo: a hierarchy of cell fate transformations. Dev. Biol. 215, 1-12. Abstract Article

All WormBook content, except where otherwise noted, is licensed under a Creative Commons Attribution License 